\title{
Dimensions of Forgiveness and the Influential Factors in Infertile Couples
}

\author{
Samaneh Safari ${ }^{1}$, Seyedeh Batool Hasanpoor Azghady ${ }^{2}$, Ali Asghar Ghafarizadeh ${ }^{3}$, \\ Leila Amiri Farahani ${ }^{4}$
}

\begin{abstract}
Background \& Aims: Infertility is an important life crisis that leads to psychological complications and severely stressful experiences. Infertility stress disrupts marital adjustment, and the subsequent incompatibility increases over time. In this regard, numerous factors may affect couples' relationship, and forgiveness between couples has been suggested as a major influential factor in family strength. Forgiveness could a potent mechanism to end a broken relationship or help resolve conflicts between couples and provide the conditions for reconciliation, thereby increasing couples' satisfaction with each other. Couples' forgiveness is a process that allows gaining a greater understanding of themselves, each other, and their relationships in order to become free of the dominance of negative thoughts, feelings, and behaviors after experiencing an unpleasant interpersonal event. To date, no studies have investigated the influential factors in forgiveness, and no interventional research has been focused on forgiveness in infertile couples in Iran. Prior to forgiveness-based interventions, it is essential to evaluate the dimensions and influential factors in different research communities, so that the design and formulation of support programs for infertile couples would be based on the related variables to achieve the desired outcomes. The present study aimed to assess the dimensions of forgiveness and its influential factors in infertile couples.

Materials \& Methods: This cross-sectional study was performed on 200 infertile couples referring to Omid Royan Infertility Center in Arak, Iran; the cause of infertility was of the female origin. The subjects were selected via continuous sampling during December 2018-September 2019. The inclusion criteria were Iranian nationality, age of 18-49 years, literacy, no drugs abuse, no use of medications for mental disorders, no psychiatric disorders (self-report of subjects), no adopted children, first marriage in both couples, and a minimum of one year since the diagnosis of infertility. Data were collected using demographic and infertility questionnaire and family forgiveness scale (FFS). Face and content validity was used to assess the validity of the demographic and infertility questionnaire. FFS was designed and developed by Pollard et al. in 1998 to measure forgiveness in families and couples, as well as the dimensions of forgiveness. The questionnaire consists of 40 items and two sections. The first 20 items are focused on the family of origin, and the second 20 items are focused on primal relationship (nuclear family). Since the infertile couples in our study were childless, only the second section of the questionnaire (primal relationship) was used, which has five subscales of realization, recognition, reparation, restitution, and resolution. Each subscale has four items, which are scored based on a four-point Likert scale (Never True $=1$, Almost Always True $=4$ ). Notably, the 10-point scoring of this questionnaire is inverse. The scores of each subscale are within the range of 4-16, and the score range of the entire scale is $20-80$, with the higher scores indicating more forgiveness. Pollard et al. obtained the Cronbach's alpha coefficient for the subscales of the questionnaire, which are calculated to be within the range of $0.55-0.86$. FFS has been psychometrically measured for the Iranian population by Seif and Bahari (2003). In a study on a sample of 766 married couples in Tehran (Iran), the reliability of the second section of the scale (primal relationship) was reported to be $85 \%$ based on Cronbach's alpha. Data analysis was performed in SPSS version 16 using independent t-test, Mann-Whitney
\end{abstract}

\footnotetext{
1. Department of Midwifery \& Reproductive Health, School of Nursing and Midwifery, Iran University of Medical Sciences, Tehran, Iran

${ }^{2}$. Nursing Care Research Center (NCRC), Department of Midwifery \& Reproductive Health ,School of Nursing and Midwifery, Iran University of Medical Sciences, Tehran, Iran (Corresponding author) Tel: 09155031928

Email: hasanpoor.sb@iums.ac.ir

3. Jihad University of Markazi Province, Omid Royan Infertility Treatment Center, Arak, Iran

${ }^{4}$. Nursing Care Research Center (NCRC), Department of Midwifery \& Reproductive Health ,School of Nursing and Midwifery, Iran University of Medical Sciences, Tehran, Iran
} 
U test, one-way ANOVA, Kruskal-Wallis test, and Pearson's correlation-coefficient, and the P-value of less than 0.05 was considered as significant.

Results: The mean forgiveness score of men and women was $64.38 \pm 4.89$ and $64.14 \pm 6.16$, respectively. The highest mean score in the dimensions of forgiveness in both women and men was achieved the dimension of resolution ( $14.10 \pm 1.84$ and $13.94 \pm 2.18$, respectively), while the lowest mean score was in the dimension of recognition in women and men (10.80 \pm 1.75 and $10.58 \pm 1.34$, respectively). A significant positive correlation was observed between the forgiveness of infertile women and the forgiveness of their spouses $(\mathrm{r}=0.44 ; \mathrm{P}<0.001)$. Among the studied variables, the forgiveness of infertile women was correlated with the variables of male and female education level, female occupation status, residential status, and type of marriage. On the other hand, spousal forgiveness was only correlated with male education level, male occupation status, and the number of failed pregnancies.

Conclusion: According to the results, the mean forgiveness scores of men and women had no significant difference. The highest mean score in both women and men was achieved in the dimension of recovery, while the lowest mean score belonged to the acknowledgment of error. Increased forgiveness in one of the spouses was accompanied by enhanced forgiveness on behalf of the other spouse. Among the studied variables, forgiveness in infertile women was correlated with the variables of male and female education level, female occupation status, residential status, and type of marriage, while the forgiveness of men was only correlated with male education level and occupation status and the number of failed pregnancies. Attention must be paid to the influential factors in forgiveness in the development and formulation of counseling or educational programs based on forgiveness, along with other methods of psychological support for infertile couples in order to improve marital relations and couples' adaptation to the issues and stresses caused by infertility and its treatment.

Keywords: Forgiveness, Influential Factors, Infertile Couples

\section{Conflict of Interest: No}

How to Cite: Safari S, Hasanpoor Azghady SB, Ghafarizadeh AA, Amiri Farahani L. Dimensions of Forgiveness and the Influential Factors in Infertile Couples. Iran Journal of Nursing. 2020; 33(126):69-81.

Received: 15 Jul 2020

Accepted: 14 Oct 2020 


\title{
ابعاد بخشودتى و عوامل مرتبط با آن در زوجين نابارور
}

\author{
سمانه صفرى'، سيده بتول حسن :يور ازغدى '، على اصغر غفارى زادهّ، ليلا اميرى فراهانى
}

\section{"جكيده}

زمينه و هدف: بيشتر شواهد علمى اشاره به تأثير منفى نابارورى بر روابط زوجين دارند، لذا ممكن است توجه به ابعاد بخشودگى و عوامل مرتبط به آن

براى زوجين نابارور مفيد باشد، بر اين اساس مطالعهى حاضر با هدف تعيين ابعاد بخشودكى و عوامل مرتبط با آن در زوجين نابارور انجام شد.

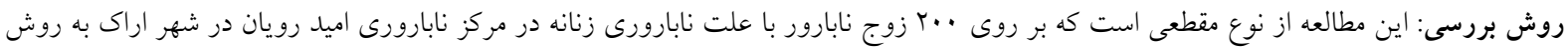

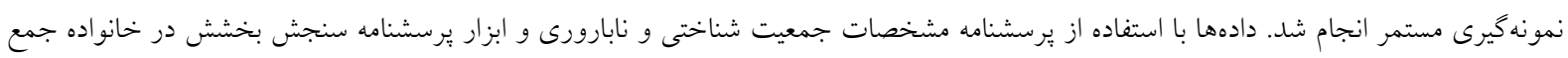
آورى شد.

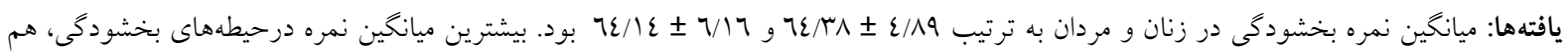

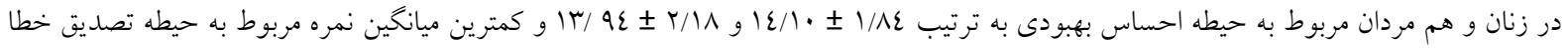

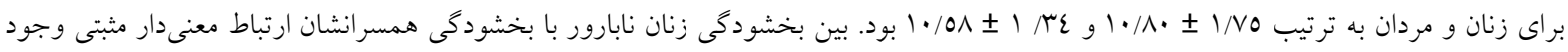

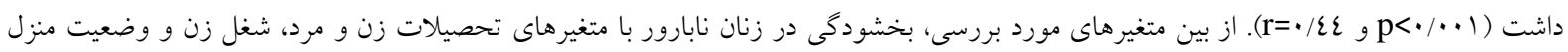

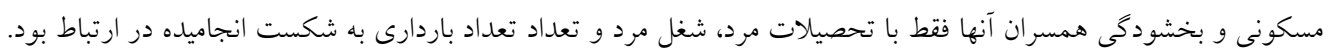

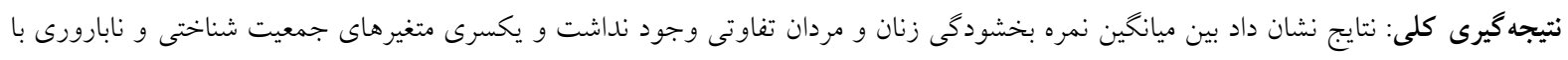
بخشودكى در زنان نابارور و همسران آنها در ارتباط بود كه توجه به اين متغيرها مىتواند در تهيه و تدوين برنامهاى مشاورهاى يا آموزشى مبتنى بر بخشودگى كمك كننده باشد.

كليد وازهها: بخشودگى، عوامل مرتبط، زوجين نابارور

تعارض منافع: ندارد

99/2/Y0 تاريخ دريافت

تاريخ بذيرش: M9/V/T

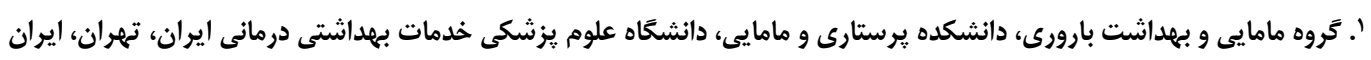

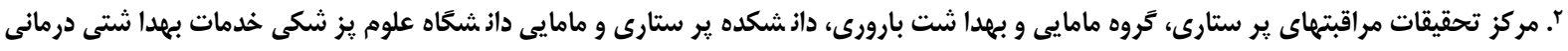
Email :hasanpoor.sb@iums.ac.irl

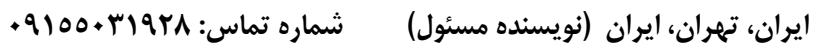

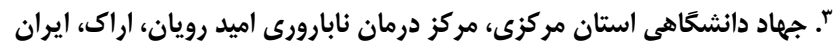

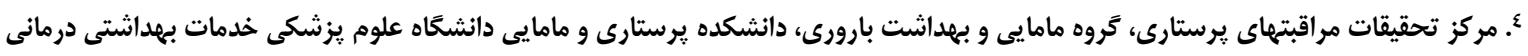
ايران، تهران، ايران 
بين زن و شوهر، همجنين رضايت زناشويى بحذارد.

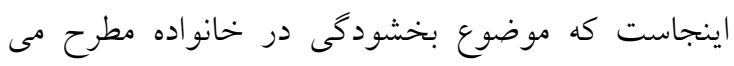
شود انجاست. در يزووهشهاى مختلف، بخشودكى در ارتباط با ديخران،

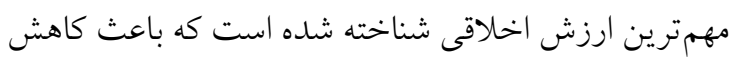
قابل توجه اثرات احساسات منفى نظير ناراحتى يا رنجش

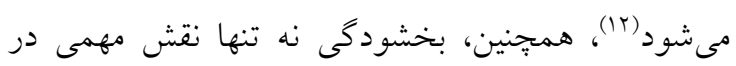
كاهش احساسات منفى دارد، بلكه به افزايش احساسات

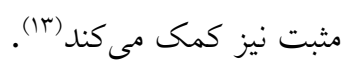

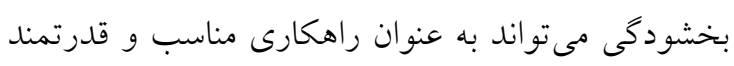

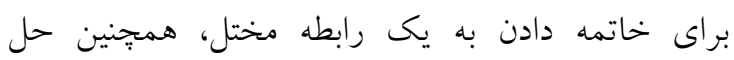
تعارضات بين زوجين كمك كند و شرايط مصالحه با فرد

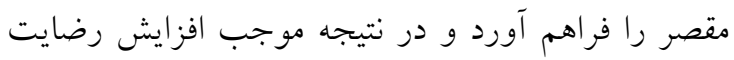

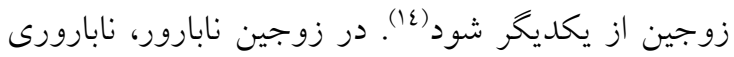

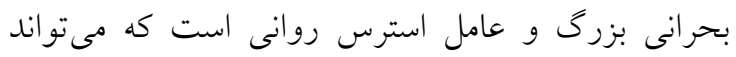

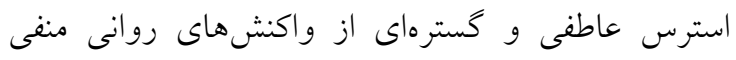

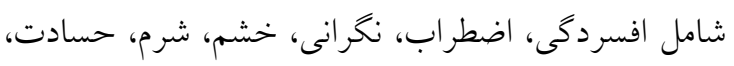

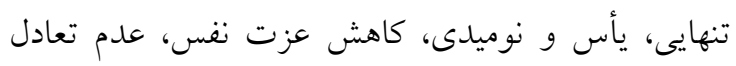
عاطفى، احساس نداشتن كفايت جنسى و اختلال عملكرد

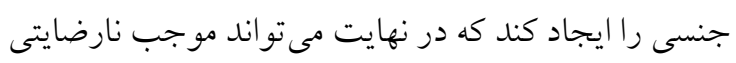

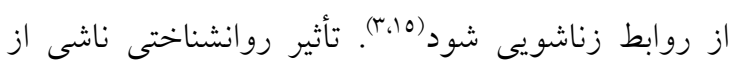

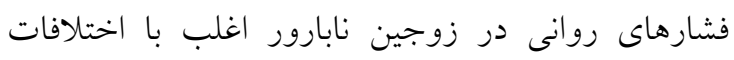

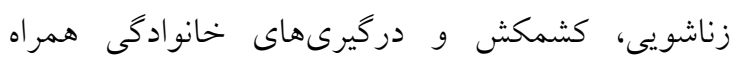

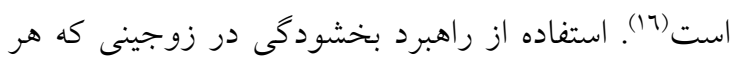

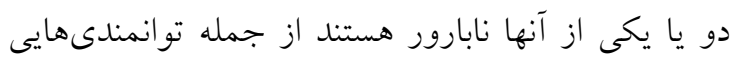

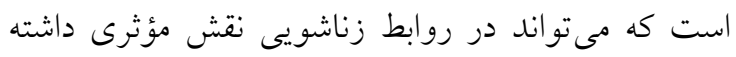

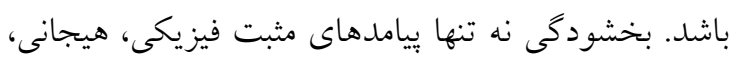
شناختى و ارتباطى را براى فرد بخشنده فراهم مى كند، بلكه

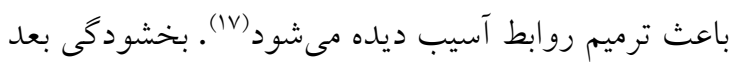
عاطفى زوجين را هدف قرار مىدهد. فراهم كردن جوى بدون تهديد به همراه توجه مثبت غير مشروط براى بيان

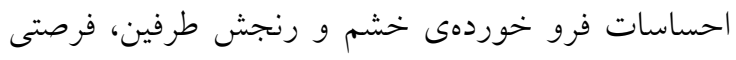
براى احياى روابط را فراهم مىكند، بنابراين احساسات

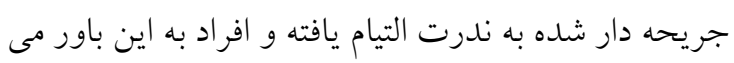

\section{مقدمه}

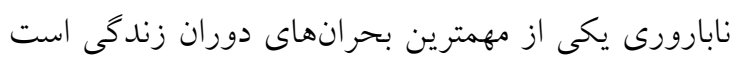

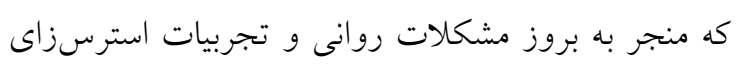

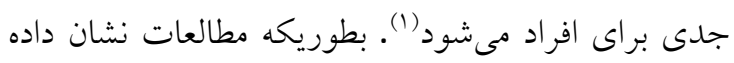

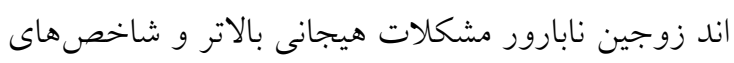
بهزيستى ضعيفترى نسبت به زوجين بارور دارند (rآT).

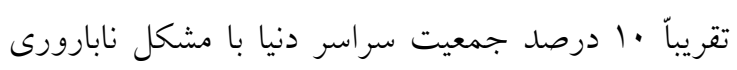

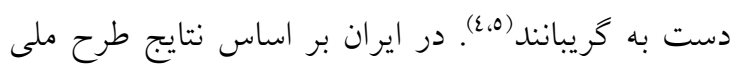

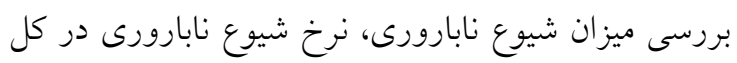

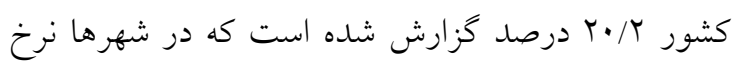

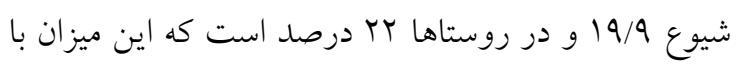

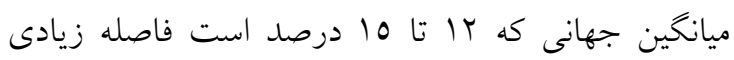
دارد

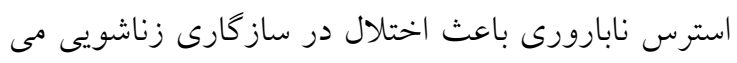

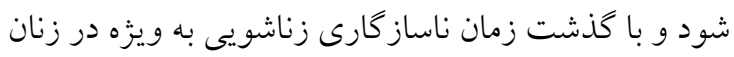

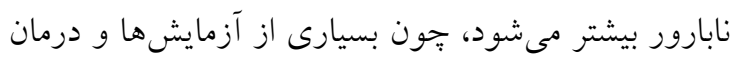
هاى مربوط به نابارورى روى زنان نابارور انجام مى شود (v).

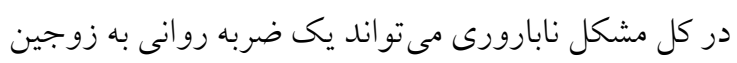
وارد ساخته و منجر به عدم تعادل روانى زوجين و كاهاً

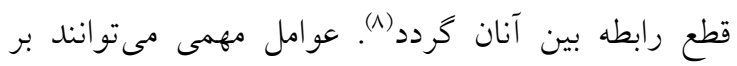
روابط زوجين اثر بحذارند كه در اين ميان بخشودكى بين بين

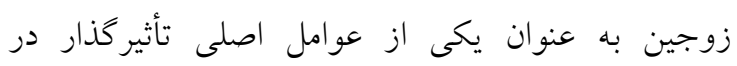

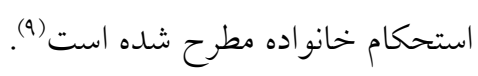
براى بخشودگى، تعريفهاى متفاوتى ارائه شده است،

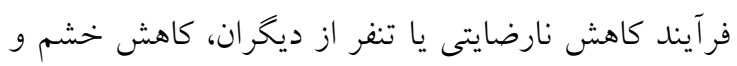

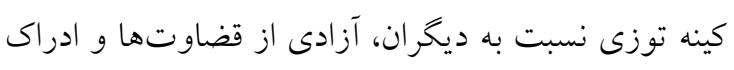

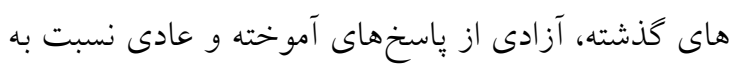

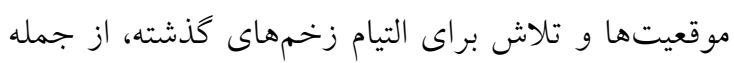

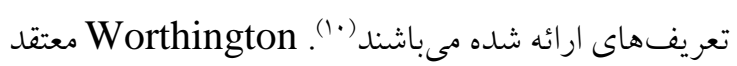
است كه اعضاى خانواده ممكن است موجب رنجش و و

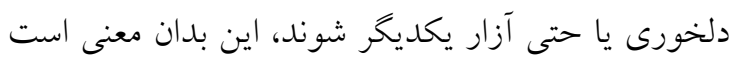

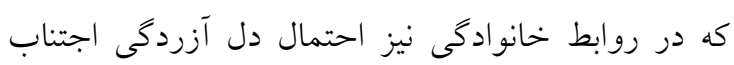

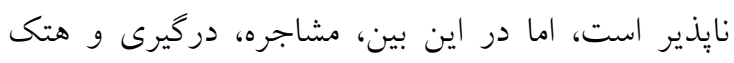

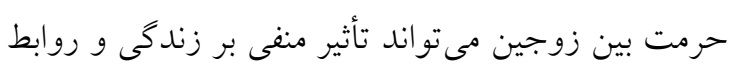


روش بروسى

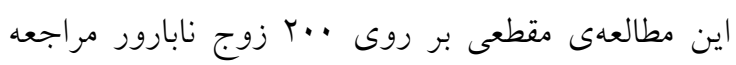

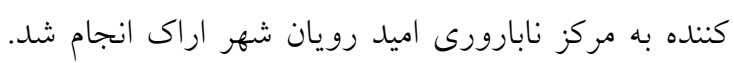

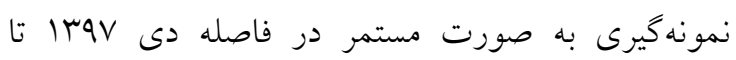

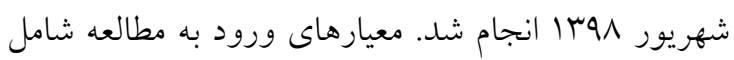

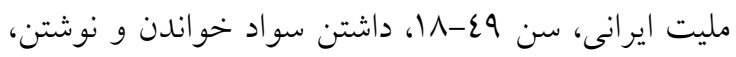

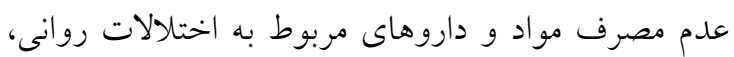

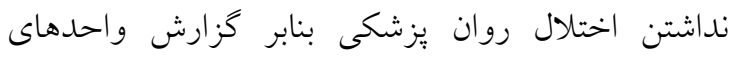

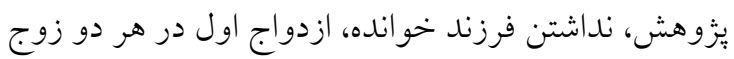

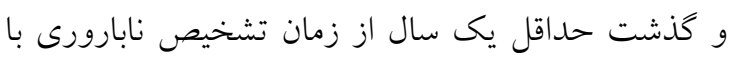

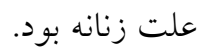

براى تعيين حجم نمونه در سطح اطمينان 90 درصد و توان

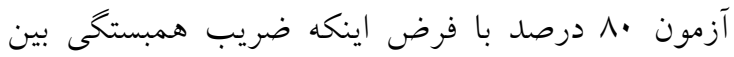
بخشودكى با مقدار بيش بينى شده توسط عوامل مرتبط حداقل rr= باشد تا اين ارتباط معنىدار تلقى كردد،

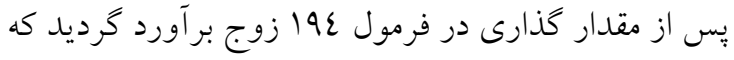

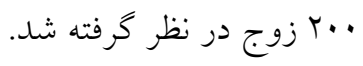

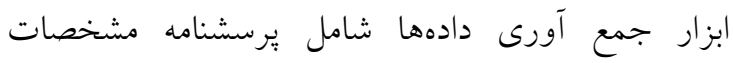

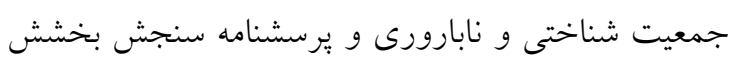

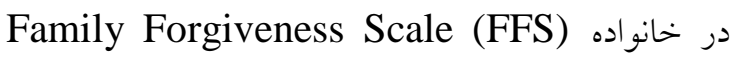
بود. جهت تعيين روايى يرسشنامهى مشخصات جمعيت شناختى و نابارورى از روايى صورى و محتوايى استفاده

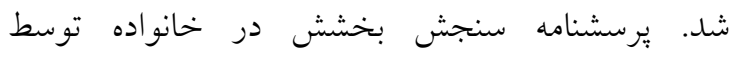
و وممكاران در سال Pollard است. بنا به اظهارات آنان اين مقياس درصدد يافتن ميزان

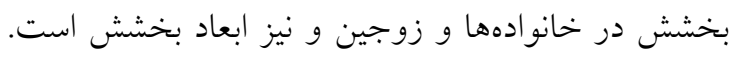

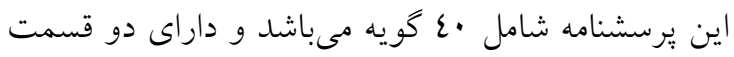

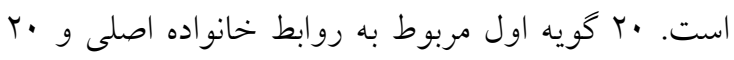

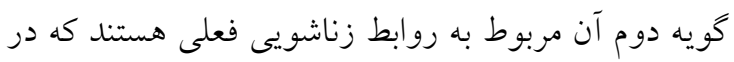
اين يزوهش جون زوجين نابارور بدون فرزند هستند، فقط قسمت دوم يرسشنامه (روابط زناشويى فعلى) مورد استفاده

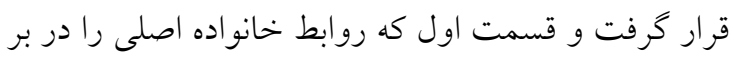

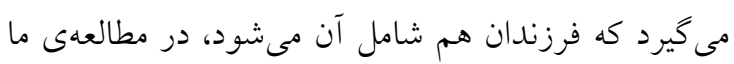
كاربردى نداشت. اين بخش شامل ينج خرده مقياس است
رسند كه كينه و نفرت فايدهاى ندارد و با بخشودگى مى إنى

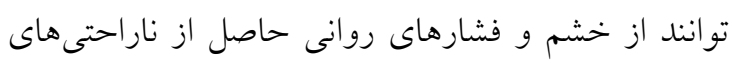

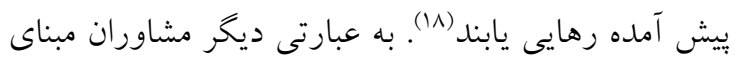

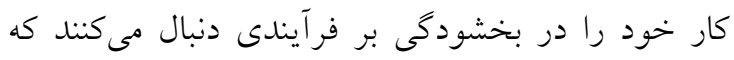

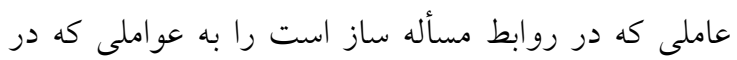

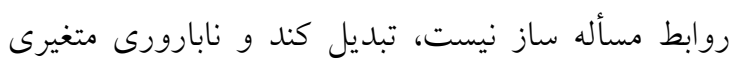

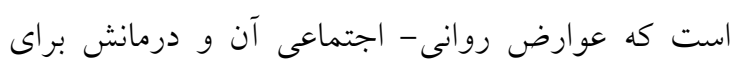

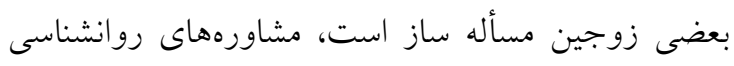

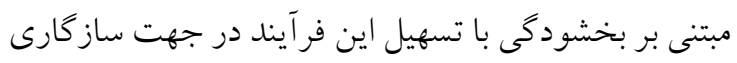

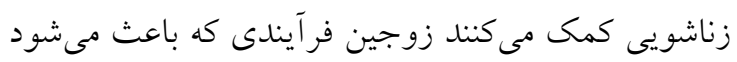

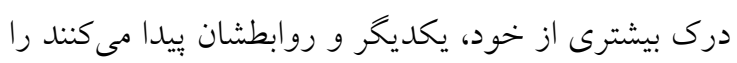

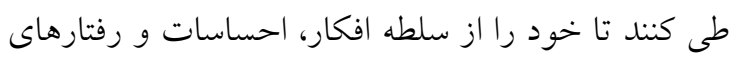

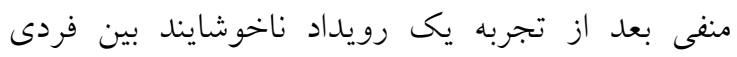

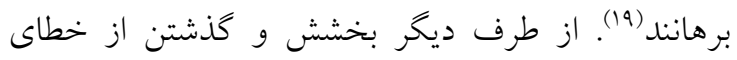

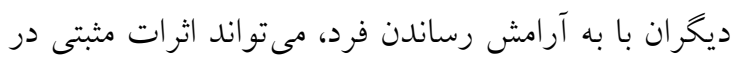
سلامتى روانى، جسمانى و حتى اجتماعى و معنوى افراد

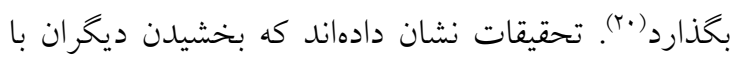
كاهش اضطراب و فشارهاى روانى موجب تنظيم شدن فشار خون، كاهش مشكلات قلبى و عروقى، افسردكى،

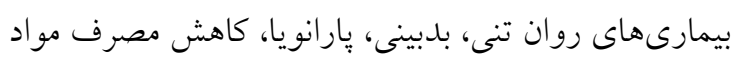
مخدر و سيخار مى شود (YT-Y).

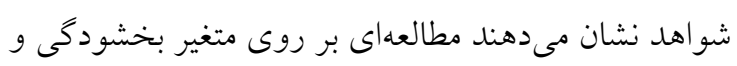

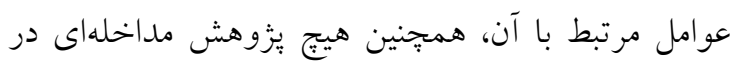

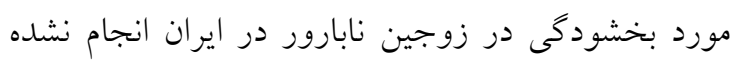

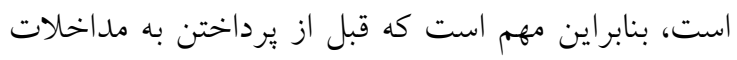

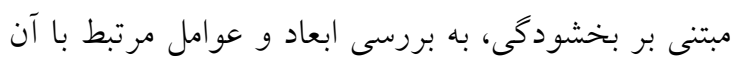

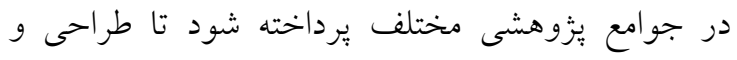

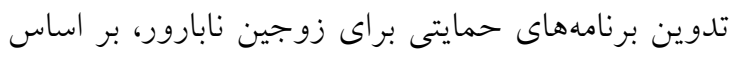

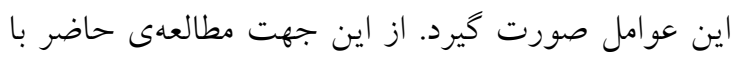

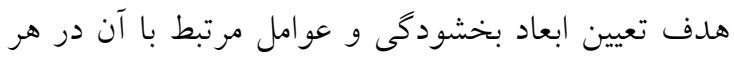
يك از زوجين نابارورانجام شد. 
يرسشنامهها در اختيار هر دو زوج جهت تكميل قرار گرفت

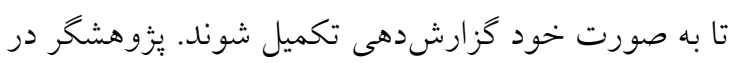

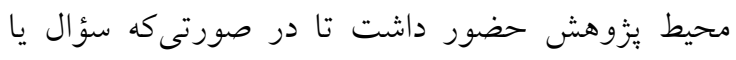

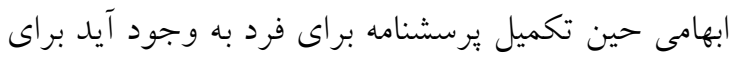

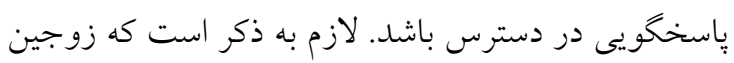

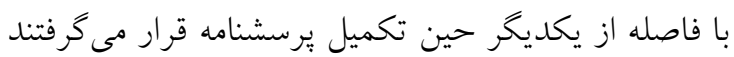

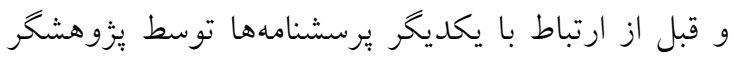

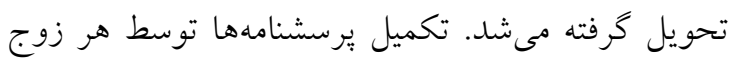
به طور متوسط شش دقيقه زمان مىبرد. تجزيه و تحليل

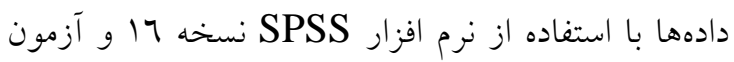
هاى آمارى تى مستقل، من ويتنى، آناليز واريانس يكىطرفه،

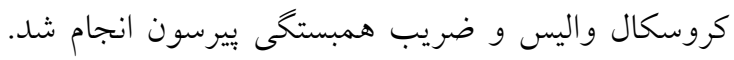

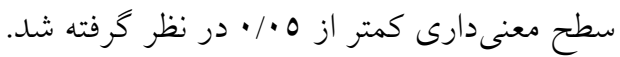

\section{يافتهها}

از آنجا كه يُزوهشخر برسشنامههايى را توسط نمونهها در

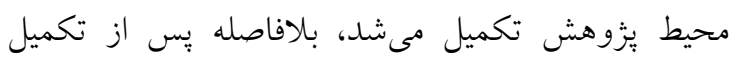

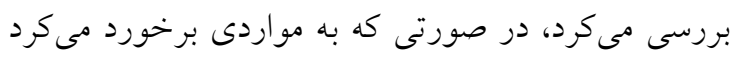

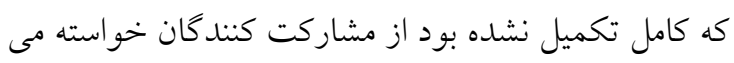

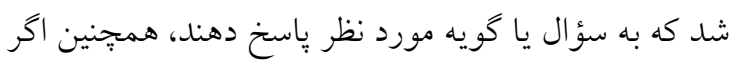

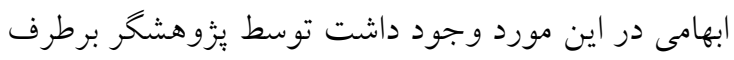

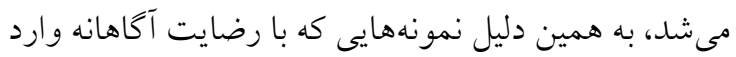
يُزوهش شده بودند يِرسشنامها را به صورت كامل تكميل و به بُزوهشخر تحويل مى دادند.

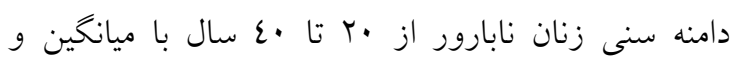

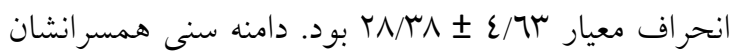
از سT تا كع سال با ميانگين و انحر اف معيار بود. اطلاعات بيشتر در مورد مشخصات جمعيت شناختى

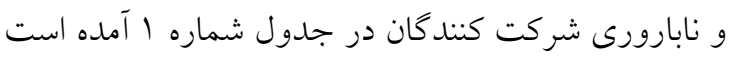
(جدول (). نمره كل بخشودگى در زنان نابارور با ميانخين نمره
كه عبارتند از: () واقع بينى (r) تصديق خطا r) جبران عمل ع) دلجويى كردن 0) احساس بهبودى يا سبكبالى. هر خرده

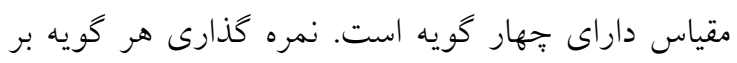

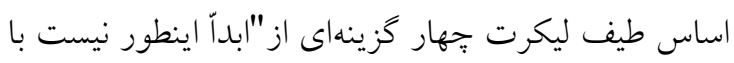

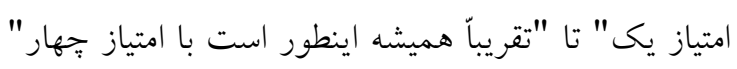

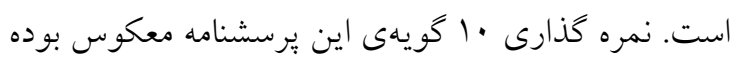
و نمرات آزمودنىها در هر حيطه از 17 -ـع است و دامنه

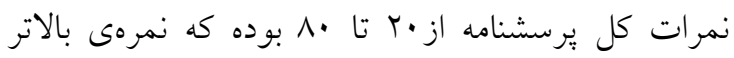

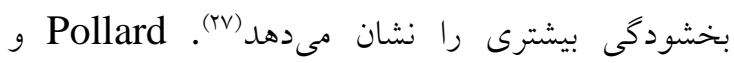

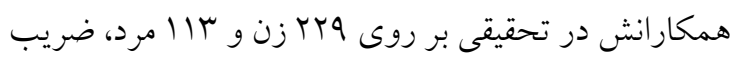

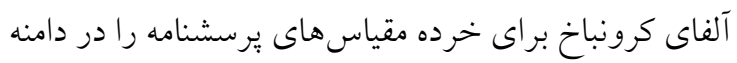

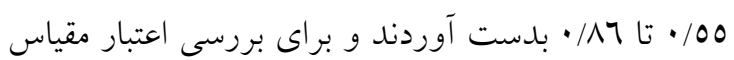

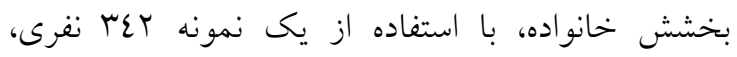

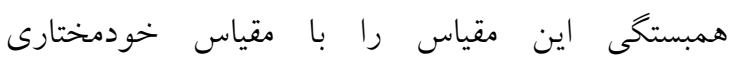
(Worthington) كردند. نتايج تحليل نشان داد كه خرده مقياسهاى اين يرسشنامه از اعتبار همخرايى مطلوبى برخوردار هستند،

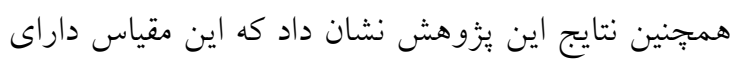

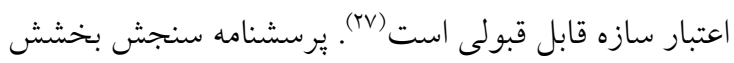

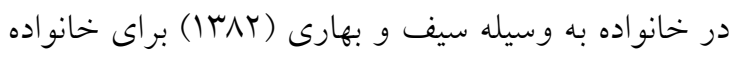
هاى ايرانى روانسنجى شد. در مطالعهاى بر روى يكى نمونه

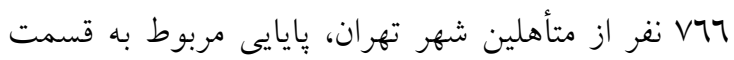

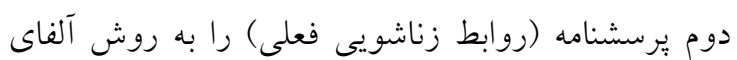

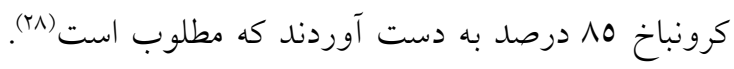
همبستگى درونى قسمت دوم يرسشنامه مورد استفاده در

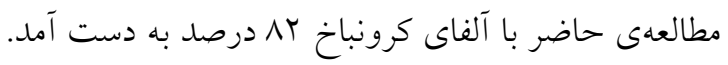

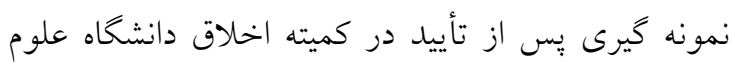
يز شكى ايران با كد (IR.IUMS.REC1396.9511482001) و دريافت مجوز از دانشگاه علوم يزشكى ايران در مركز

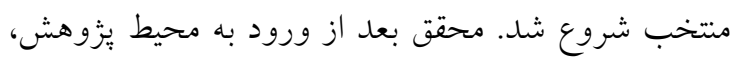

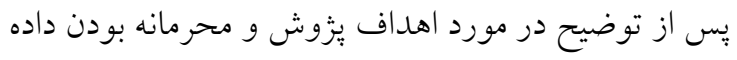

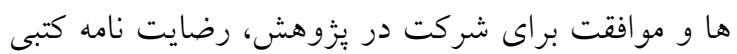

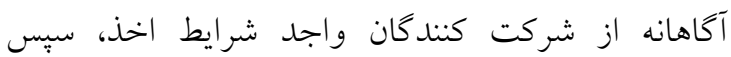


جدول شماره ا: توزيع فراوانى جمعيت شناختى زنان نابارور و همسر انشان

\begin{tabular}{|c|c|c|c|c|c|}
\hline تعداد (درصد) & & متغيرها & تعداد (درصد) & & \\
\hline$\sum V(Y \Psi / O)$ & مطلوب & & $\sum V(Y Y / O)$ & $<r_{0}$ & \\
\hline ITr (7V/0) & نسبتاً مطلوب & وضعيت اقتصادى & $0 \cdot\left(Y_{0}\right)$ & YO-YA & سن زن، سال \\
\hline$r \cdot(1 \cdot)$ & نامطلوب & & $V \cdot\left(r_{0}\right)$ & rq-rT & \\
\hline $1 \cdot \varepsilon(O r)$ & شخصى & منزل مسكونى & (17/0) & Mr & \\
\hline $97\left(\sum \Lambda\right)$ & اجارهاى & & $\sum 1(Y \cdot / 0)$ & $<r q$ & \\
\hline $1 \cdot(0)$ & $<0$ & & $7 \cdot(r \cdot)$ & $r \cdot-r r$ & سن مرد، سال \\
\hline$\left.\sum\right\rceil\left(T^{\mu}\right)$ & $0-1$. & مدت ازدواج، سال & $\sum r(Y \backslash / 0)$ & רז-r" & \\
\hline $\operatorname{l\varepsilon \varepsilon }(V r)$ & $>1$ & & $07(Y \wedge)$ & $\geq r v$ & \\
\hline $1 T O(7 T / 0)$ & $<0$ & مدت نابارورى، سال & $19 \varepsilon(9 V)$ & شهر & محل تولد زن \\
\hline Vo $(T V / O)$ & $\geq 0$ & & $\eta(r)$ & ل & \\
\hline$\| \varepsilon(O V)$ & $<r$ & & T (IT/0) & ابتدايى و سيكل & \\
\hline $0 \wedge(r q)$ & $r-\varepsilon$ & مدت درمان، سال & $91(20 / 0)$ & ديبلم & سطح تحصيلات زن \\
\hline 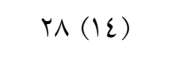 & $\geq 0$ & & $\vee\urcorner(\Upsilon \wedge)$ & دانشخاهى & \\
\hline $1 / N(91 / 0)$ & . & تعداد باردارى به & $\varepsilon \varepsilon(Y Y)$ & ابتدايى و سيكل & \\
\hline $1 \cdot(0)$ & 1 & شكست انجاميده & $\wedge\rceil(\Sigma r)$ & دييلم & سطح تحصيلات مرد \\
\hline$V(r / 0)$ & r & & $V \cdot\left(r_{0}\right)$ & دانشخاهى & \\
\hline$\wedge \cdot(\varepsilon \cdot)$ & درمان دارويى & & $111(9 \cdot / 0)$ & خانهدار & شغل زن \\
\hline r $\left(r^{\prime} / 0\right)$ & IUI & درمان در حال حاضر & $19(9 / 0)$ & شاغل & \\
\hline \multirow[t]{3}{*}{$O V(Y N / O)$} & IVF/ICSI & & $T \varepsilon(Y Y)$ & كارمند & \\
\hline & & & $1 \cdot \varepsilon(o r)$ & آزاد & شغل مرد \\
\hline & & & $M T(17)$ & كارگر & \\
\hline
\end{tabular}

طبق آزمون كروسكال واليس ميانخين نمره كل بخشودگى زنان بر حسب تحصيلات زنان نابارور و تحصيلات مرد (همسرانشان) تفاوت آمارى معنى دارى داشت. مقايسه دو به دو نشان داد بخشودگى در زنان نابارور با تحصيلات دانشخاهى بيشتر از زنان نابارور با تحصيلات ابتدايى و

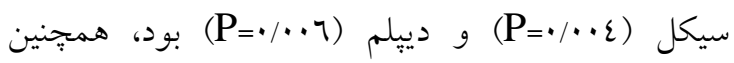
بخشودگى زنان نابارورى كه همسرانشان تحصيلات

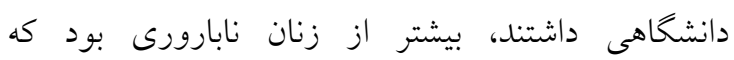

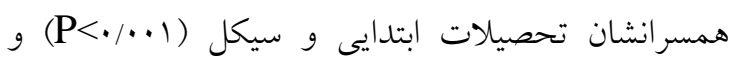

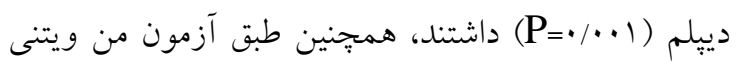
ميانگين نمره كل بخشودگى در زنان بر حسب شغل زنان از نظر آمارى تفاوت معنىدارى داشت و در خانمهاى شاغل بيشتر از خانمهاى خانه دار بود. طبق نتايج آزمون تى مستقل نيز ميانخين نمره كل بخشودگى در زنان برحسب
اطلاعات در مورد ابعاد بخشودگى هر يكى از زوجين به ترتيب در جدول شماره Y آمده است. جدول شماره Y نشان مىدهد بالاترين ميانخين نمره در حيطههاى بخشودگى هم در زنان نابارور و هم همسر انشان مربوط به حيطه احساس بهبودى به ترتيب ع/1/ كمترين ميانكين نمره مربوط به حيطه تصديق خطا براى

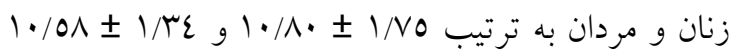
است، همجينين ضريب همبستكى بِيرسون بين ابعاد

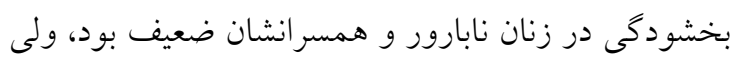
در نمره كل بخشودگى زنان نابارور با بخشودگى همسرانشان كه ارتباط معنىدار مثتى وجود داشت ضريب همبستخى (1) جدول شماره r نشان مىدهد در ارتباط با مشخصات جمعيت شناختى و نابارورى با بخشودگى در زنان نابارور، 
منزل مسكونى تفاوت آمارى معنى دارى داشت و در زنان نابارورى كه منزل شخصى داشتند بيشتر از زنان نابارورى كه منزل اجارهاى داشتند، بود.

جدول شماره ז: ميانكَين و انحراف معيار نمره بخشودمى زنان نابارور و همسرانشان به تفكيك حيطه ها و ارتباط بين بخشودمى زنان

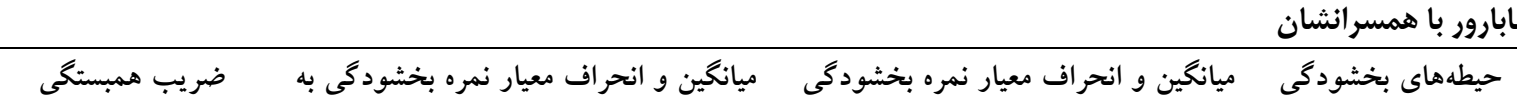

\begin{tabular}{|c|c|c|c|c|c|}
\hline \multirow[t]{2}{*}{ 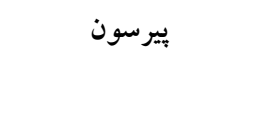 } & \multicolumn{2}{|c|}{ تفكيك حيطهها در همسران زنان نابارور } & \multicolumn{2}{|c|}{ به تفكيك حيطهها در زنان نابارور } & \multirow[b]{2}{*}{ حيطهها } \\
\hline & انحر اف معيار & ميانكين & انحر اف معيار & 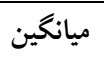 & \\
\hline $\mathrm{r}=\cdot / r 7, \mathrm{p}<\cdot / \cdot \cdot 1$ & $r / .9$ & $\mid T / T T$ & $1 / M$ & $1 T / 79$ & واقع بينى \\
\hline $\mathrm{r}=\cdot / \cdot 0, \mathrm{p}=\cdot / 2 \wedge\rceil$ & $1 / r \varepsilon$ & 1.101 & 1/No & $1 \cdot / \wedge$ & تصديق خطا \\
\hline$r=\cdot / r r, p=\cdot / \cdot . \cdot 1$ & T/17 & $15 / 19$ & $1 / N V$ & $15 / 09$ & جبران عمل \\
\hline $\mathrm{r}=\cdot / \mathrm{ro}_{0}, \mathrm{p}<\cdot / \cdot \cdot 1$ & $1 / 90$ & $\mid \pi / \wedge$. & $1 / 19$ & $15 / 19$ & دلجويى كردن \\
\hline$r=. / 11, p=. / \cdot 11$ & $r / M \Lambda$ & $\mid r / 9 \varepsilon$ & $1 / \Lambda \varepsilon$ & $\mid \varepsilon / 1$. & احساس بهبودى \\
\hline$r=\cdot / \varepsilon \varepsilon, p<\cdot / \cdot \cdot 1$ & $7 / 17$ & $T \Sigma / 1 \varepsilon$ & $\varepsilon / \wedge q$ & $7 \varepsilon / T \Lambda$ & نمره كل \\
\hline
\end{tabular}

بخشودىى در مردانى كه كارگر بودند بيشتر از مردان با

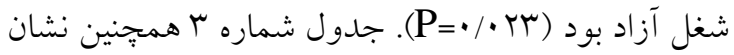
مىدهد طبق آزمون كروسكال واليس ميانخين نمره كل بخشودگى همسران بر حسب تعداد باردارى به شكست

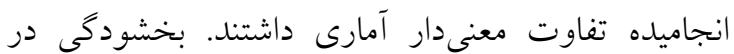

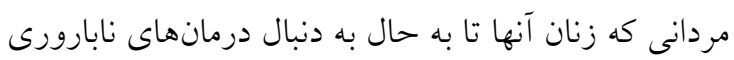

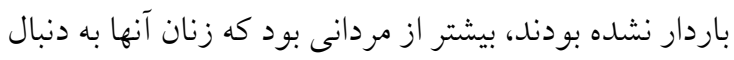

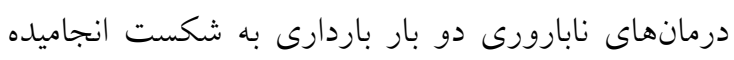

$$
\text { داشتند (rع (P=••) }
$$

در ارتباط با مشخصات جمعيت شناختى و نابارورى با بخشودحى در همسران نيز جدول شماره r نشان مى نهد

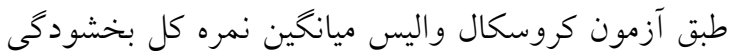
همسران بر حسب تحصيلاتشان تفاوت معنىدار آمارى

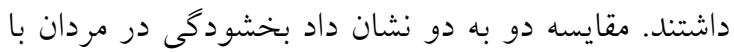

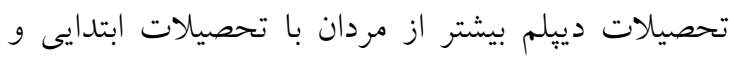

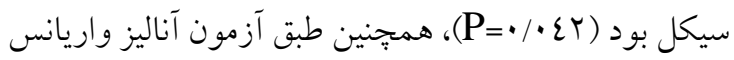

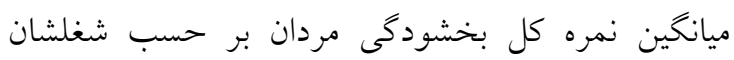

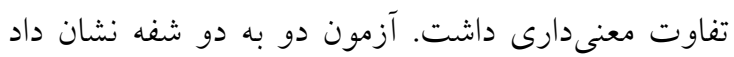

جدول شماره س: ارتباط مشخصات جمعيت شناختى و نابارورى با بخشودَى در زنان نابارور و همسر انشان

\begin{tabular}{|c|c|c|c|c|c|}
\hline \multirow{2}{*}{ 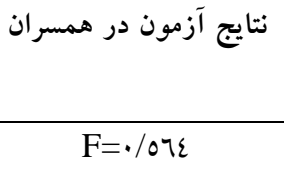 } & معيار در همسر د انحراف & نتايج آزمون در زنان & ميانگين 土 انحراف & \multicolumn{2}{|c|}{ بخشودگى زن } \\
\hline & $7 \varepsilon / V 7 \pm 0 / 0 Y$ & $F=\cdot / \varepsilon q r$ & $7 r / 90 \pm \varepsilon / 91$ & ro< & \\
\hline \multirow[t]{3}{*}{$* \mathrm{P}=\cdot / 7 \pi q$} & $\tau r / 1 \varepsilon \pm V / 10$ & $* \mathrm{P}=\cdot / 7 \wedge 9$ & $T \varepsilon / \varepsilon) \pm \varepsilon / T \varepsilon$ & rO- YA & سن زن، سال \\
\hline & $\tau \varepsilon / T V \pm T / T)$ & & $7 \varepsilon / 91 \pm \varepsilon / 9 r$ & Tq_rT & \\
\hline & $r \varepsilon / V T \pm T / T \varepsilon$ & & $\tau \varepsilon / \cdot r \pm 0 / T \Lambda$ & זrב & \\
\hline $\mathrm{F}=1 / T V T$ & $\tau r / r) \pm T / \varepsilon q$ & $\mathrm{~F}=\cdot / \mu \varepsilon \wedge$ & $7 \pi / 9 \Lambda \pm 0 / 1 r$ & $r q<$ & \\
\hline \multirow[t]{3}{*}{$* \mathrm{P}=\cdot / \Gamma \wedge 0$} & $T \varepsilon / 0 Y \pm 0 / T \varepsilon$ & $* \mathrm{P}=\cdot / \mathrm{Vq}$. & $\tau \varepsilon / A V \pm \varepsilon / T \varepsilon$ & $r \cdot-r r$ & سن مرد، سال \\
\hline & $70 / 01 \pm 0 / V \varepsilon$ & & $7 \varepsilon / 79 \pm \varepsilon / \wedge \varepsilon$ & רז-rM & \\
\hline & $\tau / \wedge r \pm T / O V$ & & $7 \varepsilon / r) \pm \varepsilon / 9 r$ & $\geq r V$ & \\
\hline \multirow[t]{2}{*}{$* * * * \mathrm{P}=\cdot / \cdot \wedge 0$} & $\tau \varepsilon / \Gamma) \pm \tau / r$ & $* * * * \mathrm{P}=\cdot /$ /9r & $\Upsilon \varepsilon / \Gamma \wedge \pm \varepsilon / 90$ & شهر & محل تولد زن \\
\hline & $0 \Lambda / 0 \cdot \pm N / Y_{1}$ & & $7 \varepsilon / 17 \pm r / 1 r$ & ل روستا & \\
\hline
\end{tabular}




\begin{tabular}{|c|c|c|c|c|c|}
\hline$* * \mathrm{df}=\mathrm{r}$ & $7 \pi / 10 \pm 7 / 17$ & $\mathrm{df}=\mathrm{r}$ & $7 r / V \wedge \pm \varepsilon / .9$ & ابتدايىوسيكل & سطح \\
\hline Chi_Square $=\cdot / r \vee 0$ & $7 r / 91 \pm 7 / 70$ & Chi_Square $=1 \varepsilon / T \varepsilon 0$ & $7 \pi / 0 \cdot \pm 0 / 20$ & دييلم & تحصيلات زن \\
\hline$* * \mathrm{P}=\cdot / \mathrm{V} \backslash \varepsilon$ & $7 \varepsilon / V 7 \pm 0 / 17$ & $* * \mathrm{P}=\cdot / \cdot 1$ & $77 / 11 \pm r / q r$ & دانشخاهى & \\
\hline$* * \mathrm{df}=r$ & $7 / / \Lambda \pm V / \Lambda$. & $\mathrm{df}=r$ & $71 / 90 \pm \varepsilon / 7 V$ & ابتدايىوسيكل & سطح \\
\hline Chi_Square $=7 /$ roq & $70 / 17 \pm 0 / 29$ & Chi_Square $=r o / / \varepsilon \vee$ & $7 r / \mathrm{NV} \pm 0 / \cdot 9$ & دييلم & تحصيلات مرد \\
\hline$* * \mathrm{P}=\cdot / \cdot \varepsilon \mathrm{r}$ & $T \varepsilon / T Y \pm O / T \Lambda$ & $* * \mathrm{P}<\bullet / \cdots 1$ & $\neg \tau / T \varepsilon \pm r / V \varepsilon$ & دانشخاهى & \\
\hline \multirow[t]{2}{*}{$* * * * \mathrm{P}=\cdot / 9 \cdot \varepsilon$} & $7 \varepsilon / 10 \pm \varepsilon / \wedge$. & $* * * * \mathrm{P}=\bullet / \bullet r$ & $7 \varepsilon / \cdot\urcorner \pm \varepsilon / \Lambda$. & خانهدار & شغل زن \\
\hline & $7 \varepsilon / 19 \pm \varepsilon / V V$ & & $T V / \varepsilon r \pm \varepsilon / V V$ & 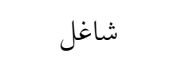 & \\
\hline $\mathrm{F}=r / \wedge \varepsilon r$ & $7 \varepsilon / \varepsilon 0 \pm 0 / V V$ & $\mathrm{~F}=\mid / r r \wedge$ & $10 / 1 \wedge \pm \varepsilon / V$ & كارمند & \\
\hline \multirow[t]{2}{*}{$* \mathrm{P}=\cdot / \cdot r \mu$} & rז/T 1 IT/ & $* \mathrm{P}=\cdot / \mathrm{T}$ VV & $7 r / 9 r \pm 0 / 1$. & آزاد & شغل مرد \\
\hline & $77 / 07 \pm 0 / 1$. & & $7 \varepsilon / T) \pm \varepsilon / \varepsilon q$ & كارگر & \\
\hline $\mathrm{df}=r$ & $T r / 9 V \pm T / 2 T$ & $d f=r$ & $7 \varepsilon / Y q \pm \varepsilon / 9 V$ & مطلوب & وضعيت \\
\hline Chi_Square $=r / \varepsilon 10$ & $7 \varepsilon / 77 \pm 0 / V$. & Chi_Square $=r / 701$ & $T \varepsilon / V \varepsilon \pm \varepsilon / V Y$ & نسبتاً مطلوب & اقتصادى \\
\hline$* * \mathrm{P}=\cdot / \wedge \Lambda$ & $7 / 1 \cdot \pm V / N r$ & $* * \mathrm{P}=\cdot /|7|$ & $7 T / 10 \pm 0 / 2 \pi$ & نامطلوب & \\
\hline $\mathrm{df}=191$ & $7 \varepsilon / \varepsilon r \pm T / 11$ & $\mathrm{t}=r / \Lambda \wedge$. & $70 / \varepsilon 1 \pm \varepsilon / 0 \varepsilon$ & شخصى & وضعيت \\
\hline $\mathrm{t}=\cdot / 77 \pi$ & سT & $\mathrm{df}=191$ & $\eta r / r\urcorner \pm 0 / \cdot r$ & اجارهاى & مسكن \\
\hline$* * * \mathrm{P}=\cdot 10 \cdot 1$ & & $* * * \mathrm{P}=\cdot / \cdots r$ & & & \\
\hline $\mathrm{df}=\mathrm{r}$ & $\tau / T \cdot \pm T / r \pi$ & $d f=r$ & $70 / \mathrm{V} \cdot \pm \varepsilon / \mathrm{V \Lambda}$ & $0<$ & مدت ازدواج، \\
\hline Chi_Square $=1 / 01 \mathrm{~V}$ & Tr/ & Chi_Square $=r / r \diamond 9$ & $7 r / 01 \pm \varepsilon / T_{0}$ & $0-1$. & سال \\
\hline$* * \mathrm{P}=\cdot / \varepsilon\rceil$ & $7 \varepsilon / \varepsilon \varepsilon \pm T / T)$ & $* * \mathrm{P}=\cdot / \wedge \wedge \vee$ & $7 \varepsilon / 0 \varepsilon \pm 0 / \cdot 1$ & $1 \cdot>$ & \\
\hline $\mathrm{t}=\cdot / \Lambda Y T$ & $7 \varepsilon / \varepsilon r \pm T / 1 r$ & $\mathrm{t}=\cdot / 0 \mathrm{rI}$ & $7 \varepsilon / O r \pm 0 / 1 T$ & $0<$ & مدت \\
\hline $\mathrm{df}=191$ & $\tau /\urcorner \pm \pm / r)$ & $\mathrm{df}=191$ & $7 \varepsilon / 1 \varepsilon \pm \varepsilon / \varepsilon \wedge$ & $\geq 0$ & نابارورى، سال \\
\hline$* * * \mathrm{P}=\cdot / \varepsilon 1$ & & $* * * \mathrm{P}=\cdot / 7 \cdot r$ & & & \\
\hline$d f=r$ & $T / N T \pm T / \varepsilon$. & $\mathrm{df}=\mathrm{r}$ & $7 \varepsilon / \cdot r \pm \varepsilon / 9 \varepsilon$ & $r<$ & مدت درمان، \\
\hline Chi_Square $=\cdot / \vee \wedge q$ & $T \varepsilon / \Lambda \mid \pm O / V T$ & Chi_Square $=r / / q r$ & $70 / \varepsilon 7 \pm \varepsilon / 1 \mathrm{~V}$ & $r-\varepsilon$ & سال \\
\hline$* * \mathrm{P}=\cdot / \mathrm{TV} \varepsilon$ & $7 \varepsilon / \varepsilon 7 \pm 7 / 11$ & $* * \mathrm{P}=\cdot / r \cdot r$ & $7 r / 0 V \pm \varepsilon / \varepsilon V$ & $\geq 0$ & \\
\hline $\mathrm{df}=r$ & $7 \varepsilon / T V \pm T / 1 \varepsilon$ & $d f=r$ & $7 \varepsilon / 07 \pm \varepsilon / \Lambda\rceil$ & . & تعداد باردارى \\
\hline Chi_Square $=r / \cdot v v$ & $7 \pi / v \cdot \pm 0 / 70$ & Chi_Square $=r / .07$ & $\pi r / 7 \cdot \pm r / 0$. & 1 & به شكست \\
\hline$* * \mathrm{P}=\cdot \cdot / \cdot \varepsilon r$ & ON/VI \pm O/Or & $* * \mathrm{P}=\cdot / r \mid V$ & $\tau T / 1 \varepsilon \pm T / V q$ & r & انجاميده \\
\hline $\mathrm{F}=\cdot / 701$ & $7 r / 0 r \pm 0 / v \varepsilon$ & $\mathrm{F}=\cdot / 0 \mathrm{r} \varepsilon$ & $7 \varepsilon / 7 \cdot \pm 0 / \mu r$ & درمان دارويى & درمان در حال \\
\hline \multirow[t]{2}{*}{$* \mathrm{P}=\cdot / 0 r \mathrm{r}$} & $\tau \varepsilon / \varepsilon q \pm 7 / r q$ & $* \mathrm{P}=\cdot / 094$ & $\tau / / 10 \pm \varepsilon / 19$ & IUI & حاضر \\
\hline & $7 \varepsilon / 71 \pm 7 / \varepsilon q$ & & $T \varepsilon / 7 \varepsilon \pm \varepsilon / T r$ & IVF/ICSI & \\
\hline
\end{tabular}

- ${ }^{*}$ One way ANOVA ${ }^{* *}$ Kruskal-Wallis ${ }^{* * *}$ Independent t-test ${ }^{* * * *}$ Mann-Whitne

IUI: Intra-Uterine Insemination

IVF/ICSI: In vitro fertilization /ntracytoplasmic Sperm Injection

نتايج اين مطالعه كه با هدف تعيين ابعاد بخشودگى و

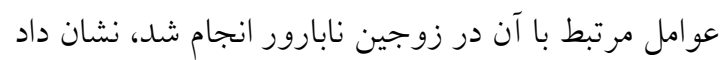


در صورتى كه در مطالعه ما بيشتر شركت كنند كان (بيش

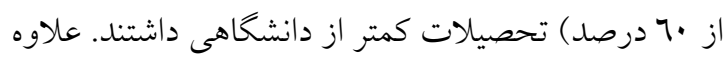

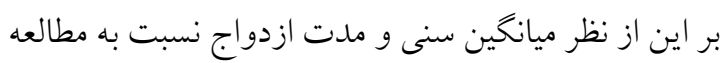

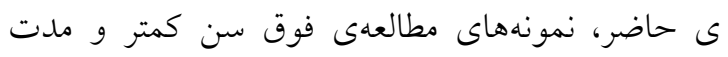

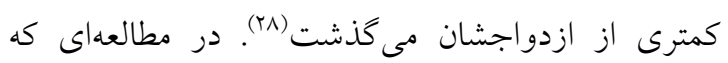

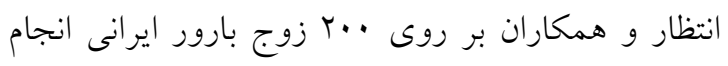

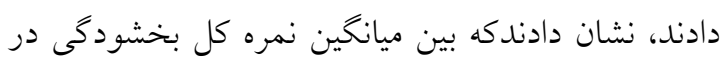

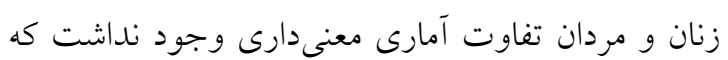

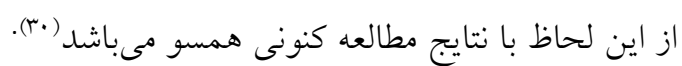

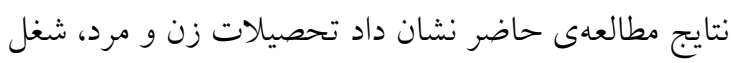
زن و وضعيت منزل مسكونى با بخشودگى زنان نابارور

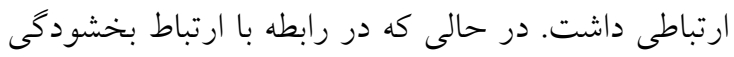

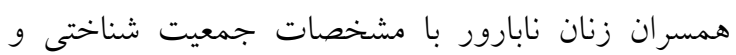

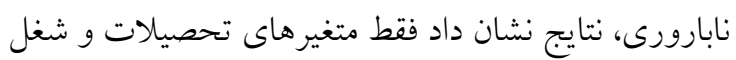

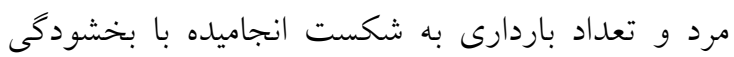
مردان ارتباط داشت. Cheng و همكاران در مطالعهاى با

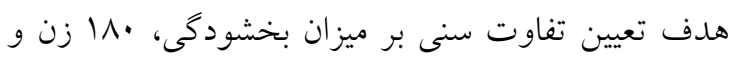

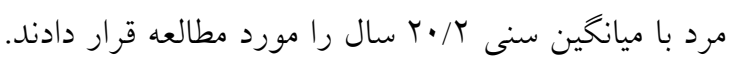

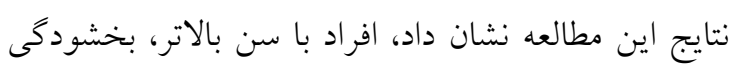

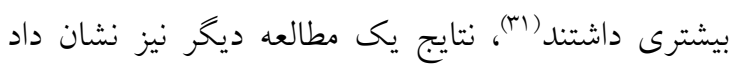

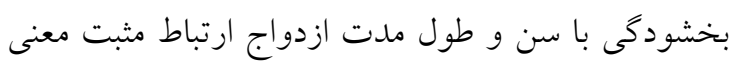

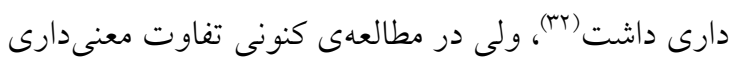

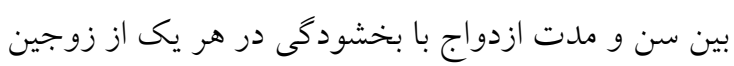

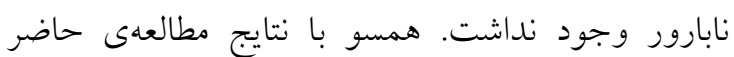

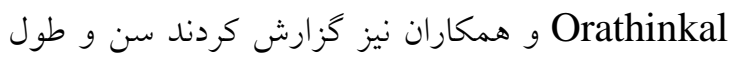

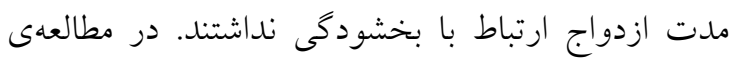
و همكاران ميزان تحصيلات رابطه مثبت معنى دارى با بخشودكى داشت كه در راستاى نتايج مطالعه

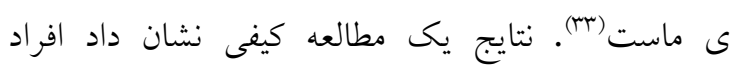

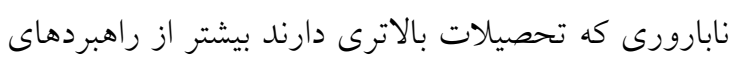

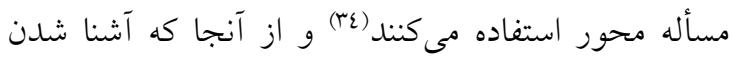

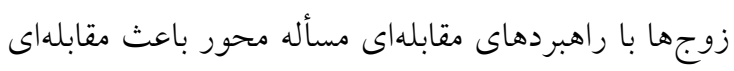

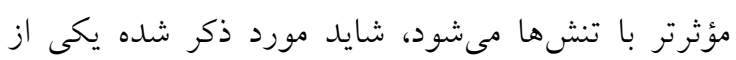
دلايلى باشد كه سبب شده تحصيلات رابطه مثبت معنى
ميانحين نمره كل بخشودحى در زنان نابارور و همسر انشان با هم تفاوتى نداشت و از ميانه ابزار بالاتر بود. بيشترين

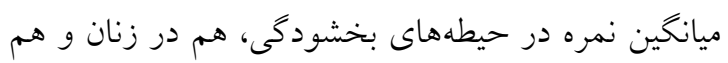
همسرانشان مربوط به حيطه احساس بهبودى و كمترين

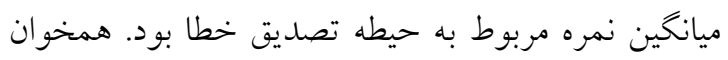

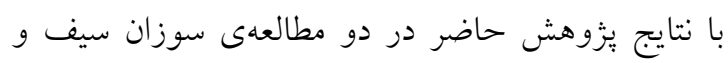

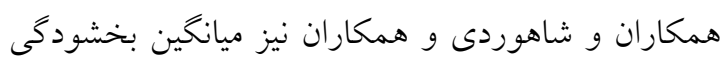

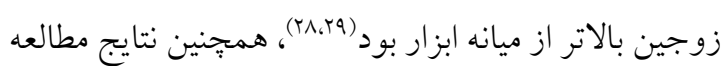
ى شاهوردى و همكاران كه در زنجان با هدف تهان تعيين بخشودگى زناشويى زوجين بارورى كه حداقل ب تا V سال

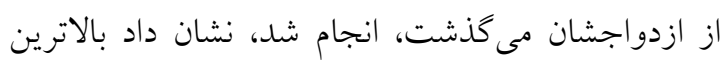
ميانكين نمره، مربوط به احساس بهبودى و كمترين نمره

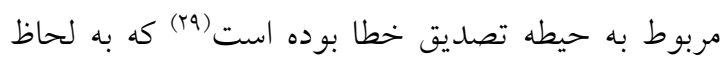

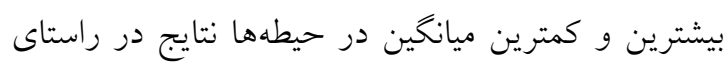

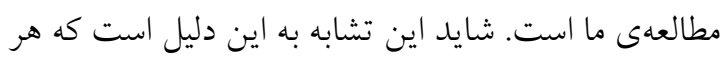
دو مطالعه تقريباً در يكى زمان و در بافت فرهنكى تقريباً

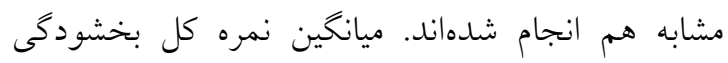

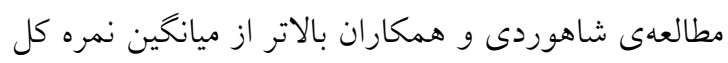

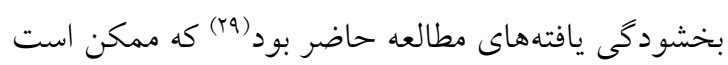

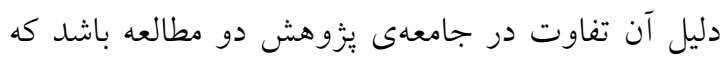

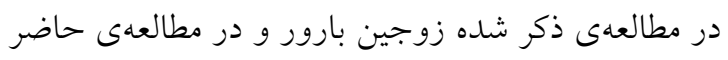
زوجين نابارور بودند. در راستاى نتايج مطالعهى حاضر سوزان سيف و همكاران

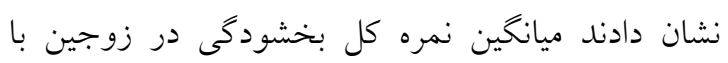

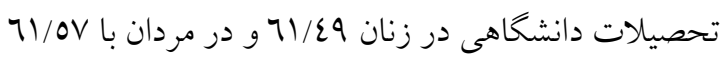

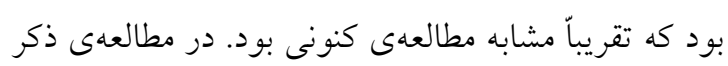

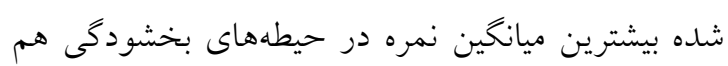
در زنان و هم مردان مربوط به حيطه دلجويى كردن و كمترين ميانخين نمره مربوط به حيطه احساس بهبودى بود مرد كه به لحاظ حيطهها، مغاير با اين مطالعه مىباشد. اين

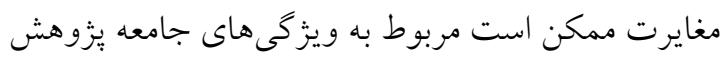

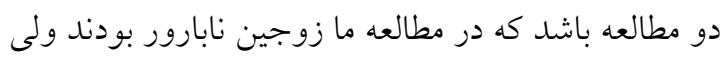
در مطالعه فوق زوجين بارور بودند، همجنين كليه شركت

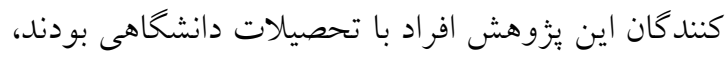


كه داراى منزل اجارهاى هستند، داشته باشند. همجنين تعداد

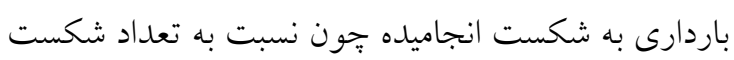
درمان بدون باردارى، علاوه بر حس ياس، نا اميدى يا

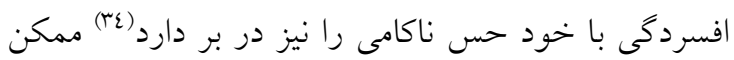
است با افزايش احساسات منفى ميزان بخشودگى را در همسران زنان نابارور كاهش دهد. لازم به ذكر است كه تمام تفسيراتى كه بر اساس تجربه جند ساله يُزوهش در حوزه نابارورى توسط بعضى از يزوهشخران اين مطالعه ارائه شده است، بهتر است توسط مطالعات صحت و سقم آن نيز بررسى شود. در مطالعهى حاضر جند محدوديت وجود داشت. شيوه جمع آورى دادهها كه بر اساس خود گزارشدهى واحدهاى يزوهش بود كه با توجه به ماهيت يزوهش، ممكن است

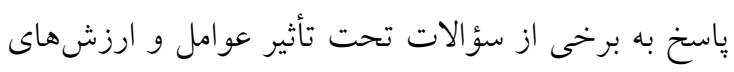
فرهنكى جامعه قرار گرفته باشد. يرسشنامه بخشودگى لئى

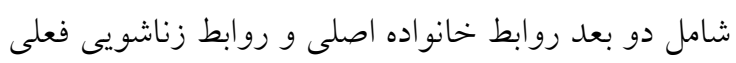
مىباشد. در اين بزّوهش كه نمونهها زوجين نابارور بودند، استفاده از بعد روابط خانواده اصلى كه شامل فرزندان هم مىشود كاربردى نداشت، به همين جهت بررسى مقايسه

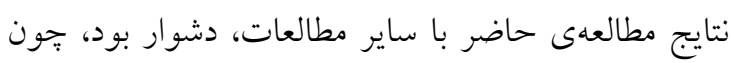
در بيشتر مطالعات به جاى ارائه نتايج مربوط به متغير بخشودگى در هر كدام از دو بعد برسشنامه به صورت جداكانه و در نهايت در كل برسشنامه، فقط به ارائه نتايج كل يرسشنامه اكتفا شده بود و به ارائه نتايج در هر يكى از دو بعد يرداخته نشده بود، بنابراين نتايج كل قابل استفاده در مطالعهى حاضر نبود. از طرف ديخر جون بر روى متغير بخشودگى و عوامل مرتبط در زوجين بارور مطالعات بسيار كمى انجام شده بود و در زوجين نابارور هيج مطالعهاى انجام نشده بود، در قسمت بحث مقاله با وجود جستجوهاى كسترده، محققين به مقالات اندكى براى مقايسه عوامل مرتبط با يافتههاى مطالعهى حاضر دست

يافتند.

نتايج مطالعه حاضر نشان داد بين ميانخين نمره بخشودگى زنان و مردان تفاوتى وجود نداشت و از بين متغيرهاى مورد
دارى با بخشودگى داشته باشد. Orathinkal و همكاران همجنين كزارش كردند كه جنسيت تأثير معنىدارى در برد بخشودگى زوجين داشت و در زنان به طور معنىدارى

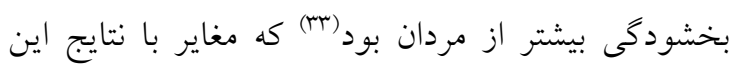

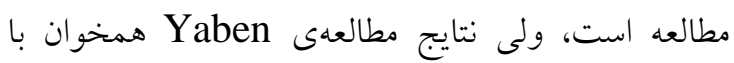
مطالعهى حاضر نشان داد بين سطح بخشش با جنسيت ارتباطى وجود نداشت، همجينين نتايج مطالعهى Yaben نشان داد سطح درآمد افراد با بخشودگى ارتباط مثبت داشت (rr)، ولى در مطالعهى حاضر تفاوتى بين وضعيت اقتصادى با بخشودگى در هر يك از زوجين نابارور وجود

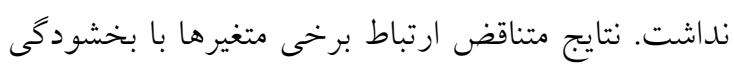
در مطالعات مختلف با يكديخر و با نتايج مطالعهى ما شايد

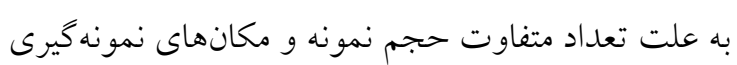
در شهرهاى بزرى و كو جكى باشد. نتايج مطالعهى حاضر نشان داد ميانخين نمره بخشودكى زنان نابارور بر حسب شغل تفاوت معنىدار آمارى داشت. ميانخين نمره بخشودكى زنان نابارور شاغل بيشتر از زنان نابارور خانهدار بود. زنان شاغل به دليل مشغوليت به حرفه اى كه دارند، كمتر بر احساسات منفى تمركز مىكنند و جون معمولاّ تحصيلات بيشترى از زنان خانهدار دارند اين دو مورد كمك مى كند كه در بعضى از حيطههاى بخشود مثل واقع بينى و دلجويى كردن نسبت به زنان خانهدار ييشروتر باشند (ع). در رابطه با متغير منزل مسكونى كه با

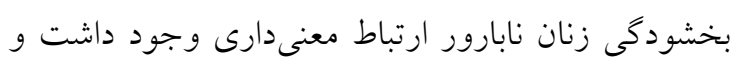
تعداد باردارى به شكست انجاميده كه با بخشودگى

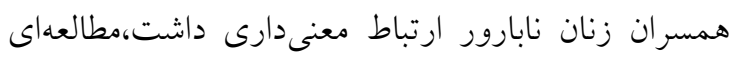
براى مقايسه با نتايج متغيرهاى ذكر شده، يافت نشد. طبق تجربياتى كه محققين اين مطالعه با زوجين نابارور داشتند شايد داشتن منزل مسكونى شخصى براى افراد نابارورى كه بايد براى درمان نابارورى، هزينه بالايى متحمل شوند، كمكى باشد تا واكنشهاى منفى زوجين مثل نخرانى و اضطراب ناشى از فراهم كردن هزينهاى زندگى و درمان كاسته شود و به دنبال روابط متعادلتر بين زوجين سبب شود زنان نابارور بخشودگى بيشترى نسبت به همتايان خود 


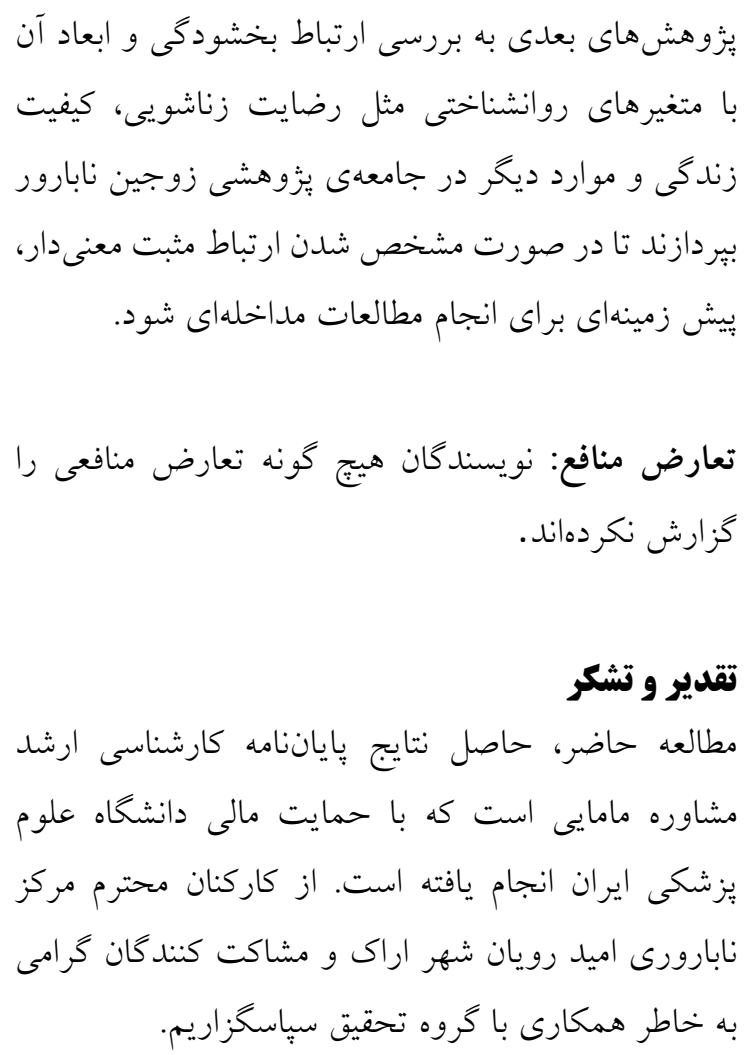

\section{References}

1. Direkvand Moghadam A, Delpisheh A, Sayehmiri K. The prevalence of infertility in Iran, a systematic review. The Iranian Journal of Obstetrics, Gynecology and Infertility. 2013;16(81):17. [Persian]

2. Gameiro S, van den Belt-Dusebout AW, Bleiker E, Braat D, van Leeuwen FE, Verhaak CM. Do children make you happier? Sustained child-wish and mental health in women 11-17 years after fertility treatment. Human Reproduction. 2014;29(10):2238-46.

3. Luk BH, Loke AY. The impact of infertility on the psychological well-being, marital relationships, sexual relationships, and quality of life of couples: A systematic review. J Sex Mar Therap. 2015;41(6):610-25.

4. Mormandi EA, Otero P, Bertone AL, Calvo M, Astarita G, Kogovsek N, Levalle O. Body weight increase and quality of semen: A controversial association. Endocrinología y Nutrición (English Edition). 2013;60(6):303-7.

5. Ombelet W, Van Blerkom J, Klerkx E, Janssen M, Dhont N, Mestdagh G, Nargund G, Campo R. The tWE lab simplified IVF procedure: First births after freezing/thawing. Facts, Views Vision ObGyn. 2014;6(1):45.

6. Akhondi MM, Ranjbar F, Shirzad M, Ardakani ZB, Kamali K, Mohammad K. Practical difficulties in estimating the prevalence of primary infertility in Iran. Int J Fertil steril. 2019;13(2):113.

7. Connolly KJ, Edelmann RJ, Cooke ID, Robson J. The impact of infertility on psychological functioning. J Psychosom Res. 1992;36(5):459-68.

8. Jonaidy E, Noorani Sadodin S, Mokhber N, Shakeri MT. Comparing the marital satisfaction in infertile and fertile women referred to the public clinics in Mashhad in 2006-07. The Iranian Journal of Obstetrics, Gynecology and Infertility. 2009;12(1):7-16. [Persian]

9. Hamidipour R, Sanaee Zaker B, Nazari AM, Naghi Farahani M. Effectiveness of ForgivenessBased Marital Group Therapy on Matrimonial Satisfaction. Women's Studies Sociological and Psychological. 2010;8(4):49-72. [Persian]

10. Brush BL, McGee EM, Cavanagh B, Woodward M. Forgiveness: A concept analysis. J Holist Nurs. 2001;19(1):27-41. 
11. Worthington Jr EL, Kurusu TA, Collins W, Berry JW, Ripley JS, Baier SN. Forgiving usually takes time: A lesson learned by studying interventions to promote forgiveness. J Psychol Theol. 2000;28(1):3-20.

12. Peterson BD, Newton CR, Rosen KH, Skaggs GE. Gender differences in how men and women who are referred for IVF cope with infertility stress. Human Reproduction. 2006;21(9):2443-9.

13. McCullough ME, Worthington Jr EL, Rachal KC. Interpersonal forgiving in close relationships. J Person Soc Psychol. 1997;73(2):321.

14. Keshavarz F, Mosalanejad L, Ghavi F, Abdollahifard S, Khodabakhshi Koolaee A. Coping strategies and perceived stress in infertile couples. Journal of Client-Centered Nursing Care. 2018;4(2):80-7. [Persian]

15. Gana K, Jakubowska S. Relationship between infertility-related stress and emotional distress and marital satisfaction. J Health psychol. 2016;21(6):1043-54.

16. Danesh E, Aminalroayaei P, Nooripour LR. The relationship between resiliency, psychological well-being and marital satisfaction of infertile couples undergoing in vitro fertilization. Community Health. 2017;4(3):170-78. [Persian]

17. Tan JH, Luan S, Katsikopoulos K. A signal-detection approach to modeling forgiveness decisions. Evol Human Behav. 2017;38(1):27-38.

18. Ghafoori S, Mashhadi A, Hasan Abadi H. The effectiveness of spiritual psychotherapy based on forgiveness in order to increase marital satisfaction and prevent marital conflicts of couples in the city of Mashhad. Journal of Fundamentals of Mental Health. 2013;15(4):45-57. [Persian]

19. Rye MS, Fleri AM, Moore CD, Worthington Jr EL, Wade NG, Sandage SJ, Cook KM. Evaluation of an intervention designed to help divorced parents forgive their ex-spouse. $J$ Divorce Remarriage. 2012;53(3):231-45.

20. Chida Y, Schrempft S, Steptoe A. A novel religious/spiritual group psychotherapy reduces depressive symptoms in a randomized clinical trial. J Relig Health. 2016;55(5):1495-506.

21. Wade NG, Hoyt WT, Kidwell JE, Worthington Jr EL. Efficacy of psychotherapeutic interventions to promote forgiveness: A meta-analysis. J Consul Clin Psychol. 2014;82(1):154.

22. Mok A, De Cremer D. Overlooking interpersonal hurt: A global processing style influences forgiveness in work relationships. Eur J Work Organiz Psychol. 2015;24(2):267-78.

23. Fincham FD. Forgiveness, family relationships and health. InForgiveness and health 2015: 25570. Springer, Dordrecht.

24. Worthington Jr EL, Lavelock C, vanOyen Witvliet C, Rye MS, Tsang JA, Toussaint L. Measures of forgiveness: Self-report, physiological, chemical, and behavioral indicators. InMeasures of personality and social psychological constructs. $2015 ; 1: 474-502$.

25. Rey L, Extremera N. Forgiveness and health-related quality of life in older people: Adaptive cognitive emotion regulation strategies as mediators. Journal of health psychology. 2016 Dec;21(12):2944-54.

26. Fincham FD. Forgiveness, family relationships and health. InForgiveness and health. 2015:25570.

27. Pollard MW, Anderson RA, Anderson WT, Jennings G. The development of a family forgiveness scale. J Fam Therapy. 1998;20(1):95-109.

28. Seyf S, Bahari F, Khosravi Z. Forgiveness scale extended to the iranian families. Women Stud. 2006;3(3(9)):97-112. [Persian]

29. Shahverdi M, Hayati M. The Effectiveness of Consolidated Couple Therapy on couples' marital forgiveness. Rooyesh-e-Ravanshenasi Journal (RRJ). 2019;8(8):149-56. [Persian]

30. Koochak R, Othman N, Binti A, Ghanbari A. Relation between emotional intelligence and forgiveness with marital satisfaction. Int J Fundam Psychol Soc Sci. 2011;1:21-5.

31. Cheng ST, Yim YK. Age differences in forgiveness: The role of future time perspective. Psychol Aging. 2008;23(3):676.

32. Yárnoz Yaben S. Forgiveness, attachment, and divorce. J Divorce Remarr. 2009;50(4):282-94.

33. Orathinkal J, Vansteenwegen A, Burggraeve R. Are demographics important for forgiveness?. The Family Journal. 2008;16(1):20-7.

34. Hasanpoor-Azghady SB, Simbar M, Abou Ali Vedadhir SA, Amiri-Farahani L. The social construction of infertility among Iranian infertile women: a qualitative study. J Reprod Infert. 2019;20(3):178. 